\title{
Detection of Various Adulterants Concentration levels in Gasoline Using NI-LABVIEW
}

\author{
M.Sridhar ${ }^{1}$, M. Ravi Kumar ${ }^{1}$, J.Chandana ${ }^{1}$, S.V.Pranitha ${ }^{1}$, K.Y.Sahithi ${ }^{1}$, Chella Santhosh ${ }^{1}$ \\ ${ }^{1}$ Department of Electronics and Communication Engineering, KoneruLakshmaiah Education Foundation, Green \\ Fields, Vaddeswaram-522502, Vijayawada.
}

\begin{abstract}
The main purpose of this paper is to find the concentration of adulterants in the gasoline using density method in LABVIEW. The researches have been made in many techniques to find the adulterants in petrol. For example distillation test, chemical maker test, evaporation test, gas chromatography may measure the adulterants specifically. Even there are digital densitometers to measure the density of petrol which are expensive and need a controlled environment and there is a very small change of density even for high level of adulterants. The above reasons and techniques led the project to use the density technique in NI-LABVIEW using CRIO through load cell sensor and flow sensor. In this paper, Compact RIO is connected to LABVIEW and the density is calculated. By this paper, certain measures can be assured to the life of engine and can decrease the pollution to some extent.
\end{abstract}

Key words: Adulterants, Gasoline, LABVIEW, CRio.

\section{INTRODUCTION}

Gasoline is a composition of Carbon (83 to 85 percent), Hydrogen (10 to 14 percent), Nitrogen (0.1to 2 percent), Oxygen ( 0.05 to 1.5 percent), Sulphur (0.05 to 6 percent) and Metals (less than 0.5 percent). Adding the adulterants is one of the most common fuel adulteration practices due to huge difference in taxation between petrol and adulterants [1-4]. Adding illegal compounds can cause dangerous and undesirable social issues to fuel such as environmental risk due to toxic gas emissions i.e., carbon monoxide and nitrogen oxide, less reliability on motor vehicles and so far unfair competition to the market on fuel prices that trigger a big loss on tax revenues for the government [5]. The most common adulterants used in gasoline are kerosene, ethanol, and naphtha. But due to hydrocarbon contamination, kerosene as high potential for use as an adulterant .
In the Indian sense, mixing diesel adulterants in the gasoline, and mixing kerosene adulterants to diesel. This is because these types of adulterations are difficult for the automobile user to detect the limited way small volume percentage. For both cases, the approximate adulteration level by volume is 10 to 30 percent [4]. More than 10 percent of adulteration is financially un attractive, whereas consumers are likely to detect more than 30 percent of adulteration from engine deterioration caused by adulterated fuel quickly [6]. To test the adulteration effectively, the fuel quality must be checked at the point of distribution itself. The equipment should be compact for this purpose and the measuring process should be rapid, capable of delivering test results within a very short time [3]. Most of the physicochemical properties are made to ensure the better quality of gasoline and these tests includes: specific mass measurements, distillation analysis, octane analysis, odor based method, ultra-sonic techniques, checking properties like density, viscosity and others [6]. The new requirements however were select based on engines better functioning, rather than having adulterants illegally inserted.

\section{RELATED WORK}

Working bench for virtual laboratory instrument engineering is a graphical programming, languages in which applications are created using icons rather than test lines [9]. In a text-based programming languages instruction set the order of execution of the program where as in LABVIEW flow of data is by the nodes of block diagram which determine the order of execution virtual instruments and functions. Digital instruments are the applications for lab viewing which represent physical instrument. In lab view we built interface using collection of tools and objects. This UI is referred to as front panel [10]. Then add code to manage the front panel objects using graphical representation of the functions. It is referred to as $\mathrm{G}$ code, or block diagram code. This code is present in block diagram. 
A virtual instrument contains the components of:

- $\quad$ FRONT PANEL

- BLOCK DIAGRAM

- ICON AND CONNECTOR PANEL

\section{PROPOSED MODELLING}

There are many methods to detect adulterants in gasoline like ASTM, evaporation test, Distillation test, Fiber optical sensor, IR method etc [11].

With most commonly used materials, including petroleum products, the ASTM has created and reported the methods of tests. Many Americansocieties for testing materials tests were standardized and reported for gasoline. Some of these measures involve determining, physical and chemical properties while others provide a measure of fuel suitability from the pointing of engine output or air pollution produced for the use of mobile cars [12]. Though no particular test is conceived to assess gasoline adulteration by diesel or gas mixtures by combining kerosene, certain tests can also be used to evaluate fuel adulteration including density test, evaporation test, distillation test and gas chromatography. Some latest work research going on related to latest technologies [13-15].

\subsection{Optical fiber sensor}

Roy S (1999) posted on a technique for detecting or estimating adulterants of kerosene in gasoline in optical fiber sensor [8]. The method goes to good use of the increase in refractive index and hence the absorption of mono chromatic light in gasoline when mixing kerosene adulterants is the same.

\subsection{Density test}

The calculation of the fuel sample density is using hydrometers and wireless densitometers. The adulteration induces a density shift that could be associated with the adulterants. The benefit of the approach is this densitometer offers really better precision but yet it suffers from drawbacks that 1) The densitometers are costly and required a regulated environment and 2) The density change is very low even for high adulteration rates.

\subsection{Implementation using CRio}

Compact RIO is a real-time embedded industrial controller designed for industrial control system for National Instruments. The Compact RIO is a composite of a real-time controller, reconfigurable IO Modules (RIO), FPGA module and an expansion frame for the Ethernet. Compact RIO empowers developers through work like Micro-Experiences, with real world problems in an environment optimized for learning [10]. There are 4 chassis named chassis 0 , chassis 1 , chassis 2 , chassis 3 . In which any of the chassis can be connected. In this paper chassis 2 and chassis 3 is used. Chassis 2 is used to find the mass using load sensor and chassis 3 , for finding the volume using flow sensor.

Many methods have been implemented to get the result of the paper as discussed above. The methods that have been implemented may get the correct response or there may be modules that to be installed or added to get the adulterants in petrol. The density technique is adapted by analyzing the techniques or methods before [4]. The density test using densitometers have limitations due to accuracy, cost and other reasons [7]. The implemented method in this paper gives the density by using a formula mass upon volume. In this paper, mass is calculated using load cell sensor which is commonly used in weighing machines and the volume is calculated by the number of pulses obtained in graph by using NI LABVIEW and CRIO.The volume is actually the liters of petrol passed. Instead of doing it manually we can get the volume by this paper. The malpractices like adulterants and the changing the desired quantity of petrol can be detected by using this technique. The density is obtained after finding the mass andVolume by using the formula of density. Thedensity ofpetrol is actually $748.9 \mathrm{~kg} /$ cubic meter. But $10 \%$ of kerosene and ethanol is allowed in petrol. By allowing the certain allowed percentages of adulterants in petrol, the density changes. After calculating the density, the message should be displayed according to the density value using LABVIEW.

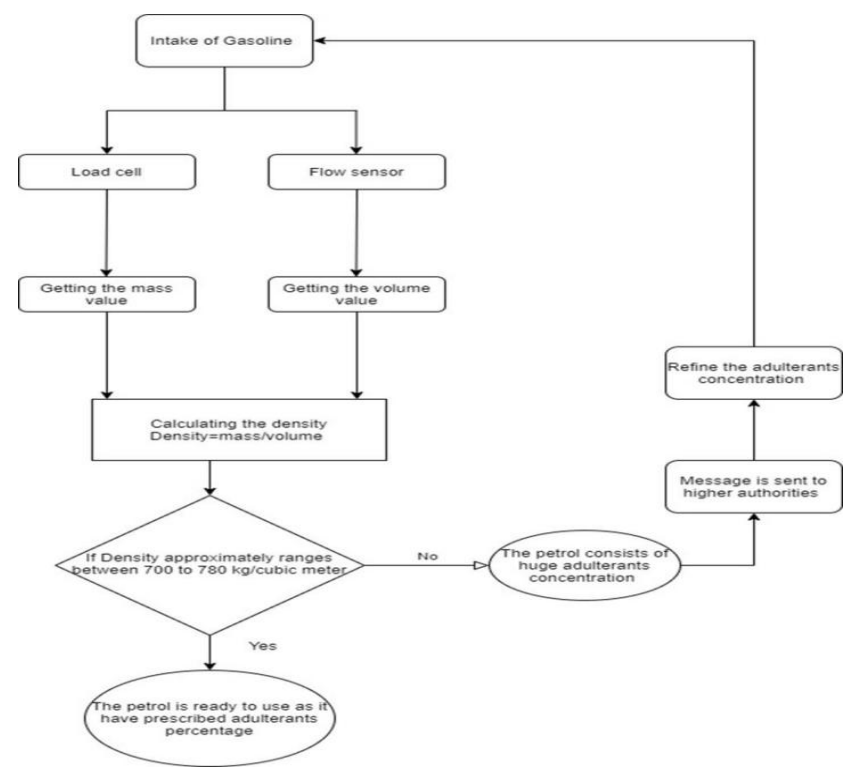

Figure 1: Flow of entire process 
Figure 1 shows the flow chart of the entire process that has been performed in this project. Load cell sensor is used to obtain the mass while flow sensor is used to obtain the volume. Using both mass and volume calculate the density of the petrol and kerosene. As,

\section{Density $=$ Mass/Volume}

If density ranges $\mathrm{b} / \mathrm{w} 700$ to $780 \mathrm{~kg} / \mathrm{m}^{3}$, petrol is ready to use. Elsewhere, petrol consists of huge adulterants concentration and this information will be sent to the authorities.

\section{RESULTS AND DISCUSSION}

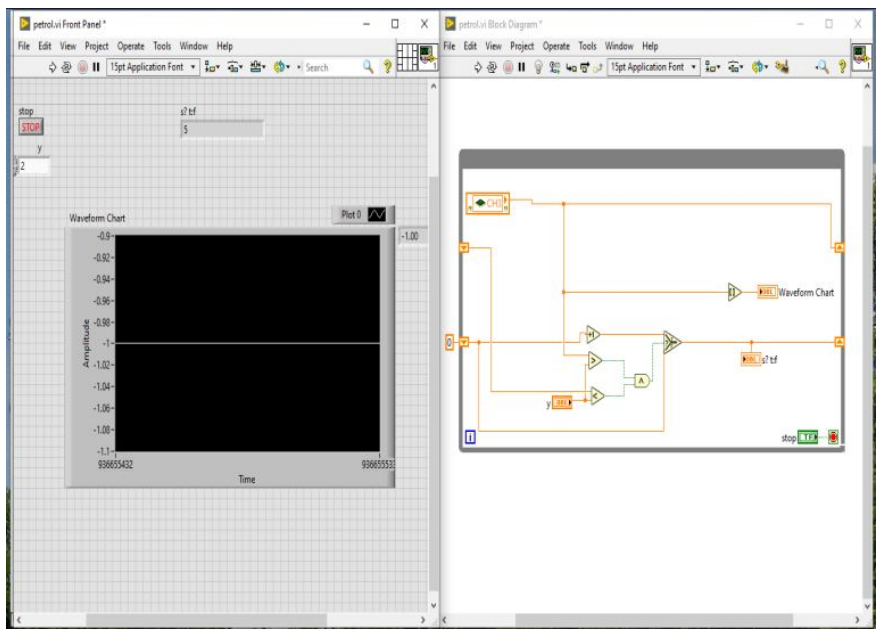

Figure 2: Front and control panel to find volume

The above Figure 2 shows in NI-LABVIEW gives the count of pulses obtained by passing the gasoline. The count gives the volume of the gasoline. In the Figure 2, the number of pulses are 5 that means $500 \mathrm{ml}$ of gasoline is passed into the flow sensor. Flow sensor have a rotor inside it which rotates when a liquid is passed into it. In NI-LABVIEW, by using the graph chart the count of pulses are obtained.

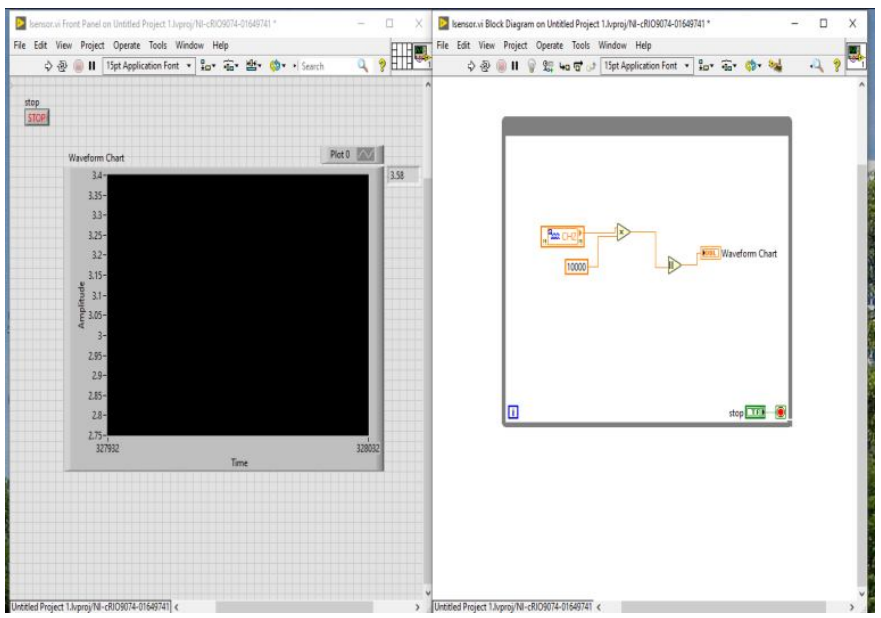

Figure 3: Control and Front panel to find mass
To get density of gasoline, both mass and volume is required. As volume is calculated through number of pulses using flow sensor. Mass is obtained by using load sensor where the results are shown in Figure 3. To calculate mass using load sensor, the same amount of gasoline is taken into a beaker and placed on load sensor, the strain gauge inside the sensor have Wheatstone bridge which undergoes tension and compression and gives the mass of the object placed.

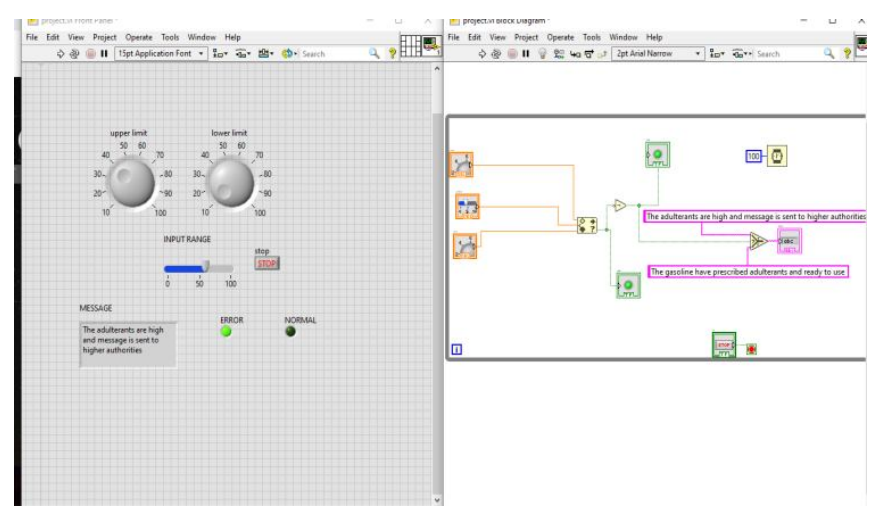

Figure 4: Front and Control panel to display message

After getting the density value, the obtained density should be checked whether it is in the range and the alert message should be displayed if it is not in the range. As mentioned in the flow chart i.e., Figure 1, Figure 4 is designed to get the alert message to customers and higher authorities about the concentration of adulterants.

Table 1: Density values of different composition of gasoline.

\begin{tabular}{|c|c|c|c|c|}
\hline S.NO & $\begin{array}{c}\text { PETROL } \\
(\mathbf{m l})\end{array}$ & $\begin{array}{c}\text { KEROSENE } \\
(\mathbf{m l})\end{array}$ & $\begin{array}{c}\text { MASS } \\
(\mathbf{g m})\end{array}$ & $\begin{array}{c}\text { DENSITY } \\
\left(\mathbf{k g} / \mathbf{m}^{\mathbf{3}}\right)\end{array}$ \\
\hline $\mathbf{1}$ & 50 & 0 & 36.60 & 732 \\
\hline $\mathbf{2}$ & 40 & 10 & 37.50 & 750 \\
\hline $\mathbf{3}$ & 35 & 15 & 38 & 760 \\
\hline $\mathbf{4}$ & 30 & 20 & 38.40 & 768 \\
\hline $\mathbf{5}$ & 25 & 25 & 39 & 780 \\
\hline $\mathbf{6}$ & 20 & 30 & 39.40 & 788 \\
\hline $\mathbf{7}$ & 10 & 40 & 40.30 & 806 \\
\hline $\mathbf{8}$ & 0 & 50 & 41.40 & 828 \\
\hline
\end{tabular}


From the table 1 , we can observe that density values from column 5 have been increased to $780 \mathrm{~kg} / \mathrm{m}^{3}$ and above which is restricted as it makes drastic damage to vehicle engine and environment.

\section{CONCLUSION}

The density values are obtained in this paper by using NI-LABVIEW. Different density values of gasoline are taken by adding kerosene into it as it is a main adulterant at present. The density values are high when kerosene is added. A small application is designed in this paper to maintain the engine life from the adulterants and giving an alert message. In this paper, the concentration of the adulterants are obtained by calculating the density. In the future scope, we can add a module that can detect the particular adulterant name for example like kerosene, ethanol etc.., and also the particular concentration of every adulterant. The effects of that adulterant can also be explained to customer.

\section{ACKNOWLEDGEMENTS}

The authors thank Mr. Anish, Project Coordinator, NI LABVIEW, Department of ECE, KLEF, and Vijayawada for his constant help throughout the project.

\section{REFERENCES}

1. L.S.M.Wiedemann, L.A.d'Avila, D.A.Azevedo. Adulteration detection of Brazilian gasoline samples by statistical analysis. (2005). Fuel and Energy Abstracts, 46(6), 360. https://doi.org/10.1016/S0140-6701(05)82939-X

2. S. Kalligeros, F. Zannikos, S. Stournas and E. Lois (2003). Fuel adulteration issues in Greece, Energy, Elsevier, vol. 28(1).

3. E.V. Takeshita, R. V. P., Rezende, S. M. A. G. U. de Souza, \& A. A. U. de Souza, (2008). Influence of solvent addition on the physicochemical properties of Brazilian gasoline. Fuel, 87(10-11), 2168-2177.

https://doi.org/10.1016/j.fuel.2007.11.003

4. A. Gupta, and R.K. Sharma, (2010). A New Method for Estimation of Automobile Fuel Adulteration. Air Pollution.

https://doi.org/10.5772/10054

5. G. Mendes, and P.J.S. Barbieri. (2013). Detection and quantification of adulterants in gasoline using distillation curves and multivariate methods. Fuel, Elsevier, 112, 163-171. https://doi.org/10.1016/j.fuel.2013.04.077

6. A. Majhi, V.S. Kukerti, Y.K. Sharma, R. Khanna, and A. Datta. (2012). The Detection of Kerosene as an Adulterant in Gasoline. Journal of Petroleum Science and Technology, Vol. 30, No. 3, pp.271-277.

7. Sh. R. Yadav, et.al. (2005)' Estimation of petrol and diesel adulteration with kerosene and assessment of usefulness of selected automobile fuel quality test parameters', International Journal of Environmental Science \& Technology, Vol. 1, No. 4, pp. 253-255. https://doi.org/10.1007/BF03325839

8. S. Roy, (1999)' Fiber optic sensor for determining adulteration of petrol and diesel by kerosene' Sensors and Actuators, B 55, p. 212-216.

9. R. M., Shrenika, S.S. Chikmath, A.V.R Kumar, Y.V. Divyashree, and R.K. Swamy, (2017). Non-contact Water Level Monitoring System Implemented Using LabVIEW and Arduino. 2017 International Conference on Recent Advances in Electronics and Communication Technology (ICRAECT).

10. M.Stepan, J. Kulhanek, and R. Wagnerova. (2015). Implementation of ESP algorithm in LabViewcRIO. Proceedings of the 2015 16th International Carpathian Control Conference (ICCC).

11. Boadu, K. O. (2019). Effects of Adulteration on Diesel Oil with Kerosene Fuel in Ghana. Journal of Applied Sciences and Environmental Management, 23(7), 1195. https://doi.org/10.4314/jasem.v23i7.1

12. Jersha Felix, V., Udaykiran, P. A., \& Ganesan, K. (2015). Fuel Adulteration Detection System. Indian Journal of Science and Technology, 8(S2), 90.

13. Chella Santhosh, K. Hari Kishore, G. Pavani Lakshmi, G.Kushwanth, P. Rama Krishna Dharma Teja, R. S. Ernest Ravindran, SreeVardhanCheerla, M. Ravi Kumar, Detection of Heavy Metal Ions using Star-Shaped Microfluidic Channel, International Journal of Emerging Trends in Engineering Research, 2019, Vol. 7, No.12, pp. 768-771. https://doi.org/10.30534/ijeter/2019/067122019

14. D VenkataRatnam, Rakesh ChowdaryGutta, M. Ravi Kumar, L. Eswara Rao, M. V. Siva Surya Reddy, P. Sai Pavan, Chella Santhosh, Effect of High-K Dielectric materials on Mobility of Electrons, International Journal of Emerging Trends in Engineering Research, 2020, Vol. 8, No.2, PP. 314-316. https://doi.org/10.30534/ijeter/2020/12822020

15. M Siva Kumar, Syed Inthiyaz, M Aditya, P Rupanjani, B Aravind, M Mukesh, Sanath Kumar Tulasi, Implementation of GDI Logic for Power Efficient SRAM Cell with Dynamic Threshold Voltage Levels, International Journal of Emerging Trends in Engineering Research, 7(12), December 2019, 902 - 906. https://doi.org/10.30534/ijeter/2019/287122019 